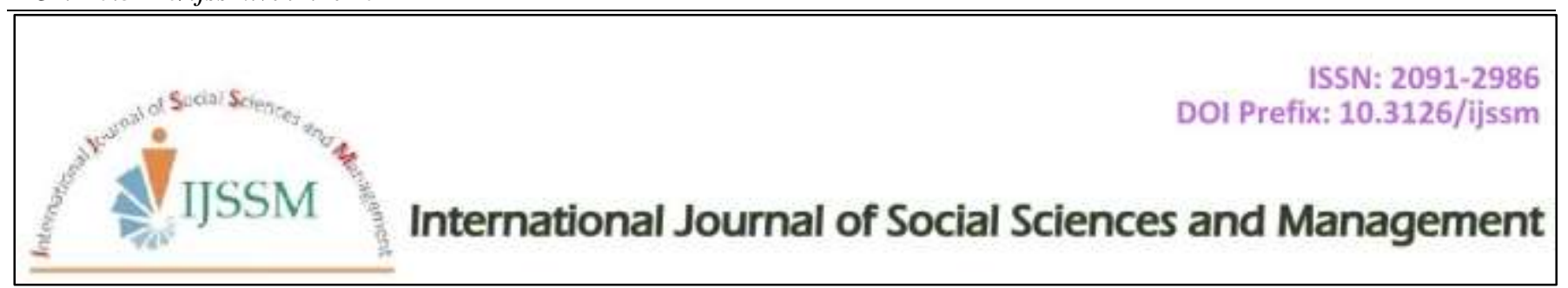

Research Article

\title{
Critical Factors of Emotional Intelligence and Its Effect on Leadership Qualities at Workplace: A Success Mantra for Effective Leaders
}

\author{
J. Shanmuganathan ${ }^{1}$, A.S. SathishKumar ${ }^{2 *}$, S. Thiriveni Sripriya ${ }^{3}$ \\ ${ }^{1}$ GITAM School of Business, GITAM Deemed to be University, Bengaluru Campus, Karnataka, India, \\ email: jeysh_423@yahoo.com, Mobile: 9597956656 \\ ${ }^{2}$ Knowledge Business School, Salem, Tamilnadu, India, email: sathishgok98@gmail.com, Mobile: 9791838508. \\ 3Jansons School of Business, Coimbatore, Tamilnadu, India, email: sripriya_423@yahoo.com, Mobile: 9585839790.
}

\section{Article Information}

Received: 06 November 2019

Revised version received: 07 January 2020

Accepted: 09 January 2020

Published: 27 January 2020

\section{Cite this article as:}

J. Shanmuganathan et al. (2020) Int. J. Soc. Sc. Manage. 7(1): 12-16.

DOI: $\underline{10.3126 / i j s s m . v 7 i 1.27404}$

\section{*Corresponding author}

A.S. SathishKumar,

Knowledge Business School, Salem, Tamilnadu, India

Email: sathishgok98@gmail.com

Mobile: 9791838508

Peer reviewed under authority of IJSSM

(c) 2020 International Journal of Social Sciences and Management

\section{OPEN AACCESS}

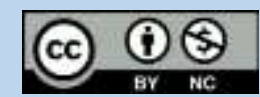

This is an open access article \& it is licensed under a Creative Commons Attribution Non-Commercial 4.0 International

(https://creativecommons.org/licenses/by-nc/4.0/)

Keywords: EI Factors; Leadership Qualities; Self-Confidence; Self-Control; Organisational Success

\begin{abstract}
At the heart of all outstanding organizations is a culture that promotes productivity and quality by valuing and creating high trust relationships. Sound business practices are essential to success, but without trusting relationships that are forged each day at all levels, organizations are limited and distracted by events and symptoms that dampen morale and discourage performance. Regardless of how sound the business practices are, the business will be limited in growth and longterm profit if strategies for integrating and valuing all people are not a part of the plan. To achieve this cultural mindset where all members of the workforce feel valued requires effort, strategy and commitment the need is for the organisations to have leaders with high emotional intelligence. Emotional intelligence has become a popular topic in the business press in recent years. Although the importance of the term "emotional intelligence" is of recent origin it has helped develop competencies that are required in many leaders. Emotional Intelligence has become a vital part of how today's leaders meet the significant challenges they face. Emotional intelligence is defined as a person's self-awareness, self-confidence, self-control, commitment and integrity, and a person's ability to communicate, influence, initiate change and accept change. Emotional Intelligence can help leaders in an ever more difficult leadership role, one that fewer and fewer people seem capable of fulfilling. And in the middle of the "Talent War", especially at the highest levels in organisations, emotional intelligence can give developing leaders a competitive edge. The idea that success in both life and in work -at least where managing people is a significant factor becomes highly credible so organisations have recognized how their best leaders and managers need to develop their understanding of themselves and others.
\end{abstract}

\section{Introduction}

Today's workforce does not accept the autocratic style often adopted by leaders following historical models of leadership. Leadership has had to evolve to match a growing

sense of democracy and independence in the workforce. Emotions are involved in everything people do: every action, decision and judgment. The people who are able to 
manage their emotional intelligent would use their thinking foe making effective decision and maintain performance in working environment. In last two decades, emotional intelligence is considering as an important indicator to assess the person 's knowledge, skills and abilities in workplace, school and personal life. The lot of studies suggested that emotional intelligence plays a significant role in job performance, motivation, decision making, successful management and leadership Employees now have an options and choices to foot their performance by managing emotions in organizational environment. Leaders now need to manage and lead their "empowered" workforce with the support of consultative, co-operative and democratic styles. These new demands includeconsultation and involvement, autonomy and freedom, opportunities for growth, challenge and glory, and inclusion and team spirit (Andoh,1998).

\section{Emotional Intelligence on Leadership}

Goleman (1998) describes in his study about the emotional intelligence and how it is effectively carried out for developing leader's ability. Three of the most important aspects of emotional intelligence for a leader's ability to make effective decisions are self-awareness, communication and influence, and commitment and integrity. Managers who do not develop their emotional intelligence have difficulty in building good relationships with peers, subordinates, superiors and clients A leader has to have emotional intelligence to align personal and subordinate goals to accomplish company goals.

Belasco and Ralph (2003) suggest four responsibilities a leader must implement at all levels of an organization. First, transfer ownership for work to the people who do the work. Second, create the environment where the transfer of ownership can take place, where each person wants to be responsible for his or her own performance. This entails painting a clear picture of what the company believes great performance is, for the company and each person; focusing individuals on the few great performance factors; developing in each person the desire to be responsible for his or her performance; aligning organization systems and structures to send a clear message as to what is necessary for great performance; engaging each individual's heart, mind and hands in the business of the business; and energizing people around the business focus.

Third, develop individual capability and competence. Fourth, create conditions in the organization that challenge every person to continually learn, including him or herself. These four principals align personal and company goals through emotional intelligence. Leaders with a high degree of Emotional Intelligence, "Do the Right Things". They come to the table with the right technical and knowledge based skills, or "table stakes". Because Emotional
Intelligence is a part of their good leadership skills, these leaders inspire and drive those around them.

\section{Leadership Qualities and Emotional Intelligence}

The enhancement of Emotional Intelligence skills can provide significant value to organizations as they seek ways to help their people develop their leadership competencies. For the past 20 years, the identification and development of leadership competencies as a means of gaining competitive advantage has been a focus of many organizations. Leadership competencies "provide organizations with a way to define in behavioral terms what its leaders need to do to produce the results the organization desires and do so in a way that is consistent with and builds its culture." Leadership in today's business world matters more than ever, and while more money is spent seeking to develop leadership competencies, the quality of leadership is still a concern (http://coach4growth.com/leadershipskills/develop-good-leadership-skills-what-is-emotionalintelligence-or-eq).

Organizations typically have a number of leadership competencies that they believe are important. Organizations want their managers and leaders to achieve improvement in as many competencies as possible in each developmental experience they are given, and Emotional Intelligence skillbuilding offers an approach to help build those competencies. Leaders demonstrating Emotional Intelligence are motivated by intrinsic versus extrinsic values. They have the desire to achieve goals, not a focus on money or prestige. The leader is optimistic, particularly during trying times. This motivation lends itself to great aspiration and accomplishment and in turn inspires those around them.

While leaders demonstrating Emotional Intelligence are persistent in the achievement of goals, they do not ignore the emotions of others. This type of leader always shows empathy for others as they have learned this is a part of good leadership skills. They strive to understand the emotional makeup of others, value diversity, and take that into consideration during interactions. Because of this desire to understand the makeup of others, they tend to build and retain talent while having a strong customer centric focus (Andoh, 1998).

Co-workers seem to appreciate managers' abilities to control their impulses and anger, to withstand adverse events and stressful situations, to be happy with life, and to be a cooperative member of the group. These leaders are more likely to be seen as participative, self-aware, composed, and balanced. Working with Emotional Intelligence, Donald Goleman suggests that some of the reasons why people derail stems from a lack of emotional intelligence. Research indicates the absence of emotional intelligence is related to career derailment. Low emotional intelligence scores are related to: 
- Problems with Interpersonal Relationships

- Difficulty Changing or Adapting

- Higher levels of emotional intelligence are associated with better performance in the following areas:

- Participative Management

- Putting People at Ease

- Self-Awareness

- Balance between Personal Life and Work

- Straightforwardness and Composure

- Building and Mending Relationships

- Doing whatever it Takes

- Decisiveness

- Confronting Problem Employees

- Change Management

Managers who don't feel a responsibility to others, who can't handle stress, are unaware of their own emotions, lack the ability to understand others, or erupt into anger easily are viewed as likely to derail due to problems dealing with other people. Self-Awareness is the key to leadership development and is a skill to handling stress. The more accurately we can identify and monitor our emotional upsets, the faster we can recover.

Self-awareness can be developed through the practice of seeking on-going feedback. Ask supervisors and coworkers who know you well for honest feedback on how your behavior is impacting them. Use opportunities to selfreflect upon adversity - business failures, demotions, missed promotions, unchallenging jobs, and personal trauma. Consider what you learned as a result of these hardships.

A massive body of research conducted over the last 60 years shows good leadership is reflected in bottom-line results. One study noted that general managers who created highperforming, energizing climates outperformed those who created neutral or de-motivating climates, delivering margins double their size. The detailers that deter a person from being a good leader are-an inability to listen, selfcenteredness, lack of self-control, know-it-all attitude, pessimism and not being a team player.

By being emotionally intelligent a person can overcome the personal traits and qualities that hinder his growth in becoming a great leader. Studies in corporations that have adopted emotional intelligence training have shown that "EI" can be trained and it is effective. There are overall improvements in productivity and profits. Up to 90 percent of the difference between outstanding and average leaders is linked to emotional intelligence.

EI is two times as important as IQ and technical expertise combined, and is four times as important in terms of overall success. Emotional intelligence increases when people commit themselves to building practical competencies in the context of everyday situations. Scientific research has uncovered a legitimate new human ability in emotional intelligence, and this has implications for developing leadership qualities. Technical and emotional factors work together in the workplace. They also illustrate how leaders who can think accurately and clearly about emotions, may often be in a better position to anticipate, cope with, and effectively manage change.

For employees, how a leader makes them feel plays a large role in their level of motivation, commitment, and even drives their brain in the best zone for marshaling whatever cognitive abilities and skills they bring to the job. And for customers and clients, how they feel about their interactions with the people in an organization determines how they feel about the company as a whole. Studies have shown that emotional intelligence is a greater indicator of success than almost any other credential.

No matter where a person is in the organization, every person must manage the stress of constant change and interact effectively with other people. Initiative, foresight, confidence and motivation are required of every person at every level today. Emotional competency is an inside-out job. It starts with one's self: developing the intrapersonal skills.

The more skilled a leader or manager is at emotional selfawareness, emotional self-regulation and emotional selfmotivation, the easier it is to pick up on the subtle social signals of others and be empathetic. Effective interpersonal skills depend largely on developing effective intrapersonal skills. The good news for leaders is that all of these competencies can be systematically learned, enhanced and developed.

\section{Analysis, Results and Discussion}

\section{Descriptive Statistics}

The Table 1 of emotional intelligence and Table 2 showing leadership quality factors describe the significance of common factors that determined the relatedness of variables. Each variables defines the individual qualities of leader and their required emotional factors that to be displayed in the workplace. The mean and standard deviation value indicates the level that has been seen in the workplace.

\section{Mean Differences}

From the Table 3, it is clear describes the significance value (p) of 0.000 for leadership quality factors which is less than the 0.05 . As a result, there is significant association between the factors of leadership qualities and also determines the basic factors of Emotional Intelligence. 
Table 1: Descriptive statistics on Emotional Intelligence factors

\begin{tabular}{|l|l|l|}
\hline Scale & Mean & SD \\
\hline Intrapersonal & 103.36 & 13.24 \\
Self-Regard & 103.78 & 11.99 \\
Emotional Self-Awareness & 102.22 & 15.90 \\
Assertiveness & 104.05 & 13.21 \\
Independence & 101.02 & 14.66 \\
Self-Actualization & 100.81 & 12.84 \\
Interpersonal & 103.62 & 13.45 \\
Empathy & 100.41 & 17.29 \\
Social Responsibility & 101.88 & 13.43 \\
Interpersonal Relationship & 103.86 & 12.81 \\
Stress Management & 105.64 & 12.86 \\
Stress Tolerance & 102.78 & 13.70 \\
Impulse Control & 106.54 & 12.48 \\
Adaptability & 104.06 & 17.14 \\
Reality Testing & 102.35 & 14.37 \\
Flexibility & 104.19 & 17.04 \\
Problem Solving & 103.63 & 14.56 \\
General Mood & 101.24 & 13.31 \\
Optimism & 101.24 & 16.61 \\
Happiness & 100.82 & 13.14 \\
\hline
\end{tabular}

Table 2: Descriptive statistics on leadership qualities

\begin{tabular}{|l|l|l|}
\hline Scale & Mean & SD \\
\hline Ambition & 6.78 & 1.68 \\
Initiative & 5.81 & 1.67 \\
Flexibility & 7.15 & 1.35 \\
Energy & 6.10 & 1.59 \\
Leadership & 5.86 & 1.74 \\
Persistence & 6.92 & 1.64 \\
Attention to detail & 7.27 & 1.56 \\
Rule-following & 5.76 & 1.70 \\
Dependability & 6.74 & 1.57 \\
Teamwork & 5.94 & 1.47 \\
Concern for others & 5.91 & 1.64 \\
Outgoing & 6.80 & 1.45 \\
Democratic & 7.47 & 1.44 \\
Innovation & 7.86 & 1.63 \\
Analytical thinking & 7.35 & 1.79 \\
Self-control & 7.83 & 1.51 \\
Stress Tolerance & 7.08 & 1.43 \\
\hline
\end{tabular}


Table 3: One sample t-test on leadership qualities

\begin{tabular}{|l|l|l|l|l|l|}
\hline Scale & Mean & SD & $\boldsymbol{t}$ & $\boldsymbol{p}$ & $\boldsymbol{d}$ \\
\hline Ambition & 6.74 & 1.70 & 29.27 & 0.00 & 0.62 \\
\hline Initiative & 6.61 & 1.69 & 26.83 & 0.00 & 0.56 \\
\hline Flexibility & 5.68 & 1.74 & 4.07 & 0.00 & 0.09 \\
\hline Energy & 7.11 & 1.59 & 40.36 & 0.00 & 0.80 \\
\hline Leadership & 5.96 & 1.64 & 11.32 & 0.00 & 0.23 \\
\hline Persistence & 7.34 & 1.53 & 48.25 & 0.00 & 0.92 \\
\hline Attention to detail & 7.04 & 1.47 & 42.01 & 0.00 & 0.77 \\
\hline Rule following & 7.59 & 1.79 & 46.73 & 0.00 & 1.05 \\
\hline Dependability & 6.82 & 1.69 & 31.51 & 0.00 & 0.66 \\
\hline Teamwork & 6.90 & 1.60 & 35.04 & 0.00 & 0.70 \\
\hline Concern for Others & 6.03 & 1.63 & 13.10 & 0.00 & 0.27 \\
\hline Outgoing & 6.61 & 1.53 & 29.10 & 0.00 & 0.56 \\
\hline Democratic & 5.79 & 1.78 & 6.44 & 0.00 & 0.14 \\
\hline Innovation & 5.90 & 1.53 & 10.48 & 0.00 & 0.20 \\
\hline Analytical thinking & 5.85 & 1.64 & 8.57 & 0.00 & 0.18 \\
\hline Self-Control & 7.17 & 1.89 & 35.41 & 0.00 & 0.83 \\
\hline Stress-Tolerance & 7.59 & 1.62 & 51.62 & 0.00 & 1.04 \\
\hline
\end{tabular}

\section{Conclusion}

Seeking to support a leader's cognitive, emotional and physical resources, the use of emotional intelligence is a modern tool of effective management, enabling the individual to manage a wide range of employees that are often performing in a unique set of roles. In addition, emotional and personal competencies are two primary factors that are shown to be directly linked to performance within a work environment, making their identification and analysis essential for effective management as well as the increased development of the organization's human capital. To climb the modern corporate ladder, a leader must be competent within their chosen field but also have a finelytuned sense of emotional intelligence. Specifically, they are typically expected to be more positive, approachable, warm, empathetic and optimistic, traits many believe to be more important than traditional cognitive intelligence in the successful achievement of workplace goals. The reason for this is due to the fact that a focus on emotional intelligence often includes the ability to contain any negative feelings and focus instead on a positive outcome - a capability that is vital for high-reaching leaders and executives.

\section{References}

Andoh ND (1998) Get Smart: I.Q. and Emotional Intelligence. Retrieved from: http://serendip.brynmawr.edu/bb/neuro/neuro01/we b3/DawsonAndoh.html

Belasco JA and Ralph CS (2003) Flight of the Buffalo: Soaring to Excellence, learning to Let Employees Lead.

Goleman D (1998). Working with emotional intelligence. New York: Bantam Books

http://en.wikipedia.org/wiki/David_Wechsler http://en.wikipedia.org/wiki/E._L._Thorndike http://en.wikipedia.org/wiki/Howard_Gardner http://eqi.org/mgtpaper.htm

http://hbr.org/2004/01/what-makes-a-leader/ar/1

http://www.ccl.org/leadership/pdf/assessments/skills_intell igence.pdf

http://www.eqi.org/eidefs.htm

http://www.lynnleadership.com/

http://www.teamtechnology.co.uk/emotionalintelligence.html 